\title{
Sustainability of Our Planet and All Species as the Organizing Principle for SLCE
}

\author{
Kevin Kecskes Jennifer Joyalle Erin Elliott \\ Portland State University
}

\author{
Jacob D. B. Sherman \\ Portland Housing Bureau
}

We may define and prioritize them differently, but few would deny that our human community is facing intractable problems at local, national, and global scales. We call on higher education institutions (HEIs) around the world to work collectively and with strategic intent and action to use sustainability as an organizing principle to focus servicelearning and community engagement (SLCE) activities on the flourishing of our planet and its diverse species.

In the United Nations report, Our Common Future, sustainable development (the future-oriented view of "sustainability") was defined by World Commission on the Environment and Development members as "the kind of development that meets the needs of the present without compromising the ability of future generations to meet their needs" (Brundtland, WCED, 1990, p. 16). Since then, scholars and practitioners have focused efforts on what has been commonly known as sustainability's "three E's": (a) environment; (b) economy, and (c) social equity (Edwards, 2005). Recently, education has been recognized as a vehicle for achieving sustainability and serves as a critical "fourth E" (UNESCO, 2016).

\section{Why Sustainability and Why Now?}

There should be little doubt that sustaining our planet and its species is the global challenge of our times. A massive income gap has grown globally during our lifetimes to stunning proportions. Oxfam (2017) recently released an analysis that the richest eight individuals in the world own as much wealth as approximately half of the world's total population. Connected to this rise in wealth inequality, the International Labour Organization recently reported that social unrest and migration increased more between 2015 and 2016 than at any time in the last four decades (Allen, 2017). Environmentally, the planet is warming at an alarming rate; NASA calls the evidence unequivocal, citing multiple studies published in peer-reviewed scientific journals that show that 97 percent or more of actively publishing climate scientists agree: Climate-warming trends over the past century are extremely likely due to human activities (Cook et al., 2016). Finally, in his most recent book, Thomashow, the past president of Unity College, suggests "sustainability is a response to a planetary emergency. We are in the early stages of the sixth megaextinction (a catastrophic loss of species), plunging declines in biodiversity, and a rapidly destabilizing climatic/oceanic circulation" (2014, p. 3).

\section{Adding Focused-SLCE Heft to Global Sustainability Action}

Although all organizations do not use the same language, it is clear that many national and international initiatives are beginning to coalesce around a call for sustaining our planet. The Anchor Dashboard (Dubb, McKinley, \& Howard, 2013) outlines economic, education, community-building, and health and environmental measures to help align higher education institutions' (HEIs) resources to address low-income community needs. Similarly, Thomashow (2014) demonstrates that infrastructure, community-building and learning approaches need to be changed to address current and emerging sustainability challenges. UNESCO (2016) notes:

\begin{abstract}
Sustainable development cannot be achieved by technological solutions, political regulation or financial instruments alone. We need to change the way we think and act. This requires quality education and learning for sustainable development at all levels and in all social contexts. . . Education for Sustainable Development (ESD) is about enabling us to constructively and creatively address present and future global challenges and create more sustainable and resilient societies (emphasis added).
\end{abstract}

Indeed, UNESCO calls for educators to develop global citizens, a topic well-researched and practiced in the SLCE domain. To this growing list of organizations and initiatives, we now add a timely and important call for the SLCE movement to consider generating a national strategic plan or set of guiding priorities (Howard \& Stanlick, 2015). 
We, therefore, have a straightforward call: HEIs need to organize around and explicitly attempt to address sustainability issues (understood most broadly as any one or more of the Four E's) through teaching, research, and community engagement. This call includes practical aspects focused on the survival of the planet's species as well as humanistic elements for social justice. Addressing the deep-seated challenges associated with sustainability - environmental degradation; persistent poverty; racial injustices; inequitable access to work, education, and health care, and especially climate change - remains a foundational challenge for HEIs to collectively address.

Given HEIs' focus on research and educating the next generation of global citizens and leaders, we urge SLCE practitioners and scholars to intentionally integrate and explicitly focus their most effective SLCE research, teaching, and learning toward sustainability-related, "place-engaged" ends (Siemers, Harrison, Clayton, \& Stanley, 2015, p. 101). This rallying cry will not only resonate with students and provide researchers with pertinent questions and value-added agendas, but also has the potential to positively change the planet by building healthy communities and better ensuring the survival of their inhabitants. It is time to leverage HEI's great strengths by combining local efforts with associated (inter)national efforts toward common, critically important sustainability ends.

\section{Strategic Thinking and Action: Nested and Reinforcing Concepts for the Long Haul}

This call positions sustainability as a meta-level organizing principle for HEIs and positions three distinct but connected organizing action strategies at the center: engaged departments, collective impact, and transdisciplinarity. At the core of the model are the key organizing delivery mechanisms of SLCE: place-engaged service-learning and community-based research (see Figure 1).

To begin, we must extend the time horizon of our thinking and action-taking; sustainability and species survival will take time and require long-term commitment. Next, we suggest that practitioners may find promise - as we and others have - in the implementation of one or more of the following organizing action strategies: engaging academic departments; collectivizing impact; and tapping transdisciplinarity.

\section{Engaged Departments}

A departmental engagement sustainability strategy requires a unified action orientation by members of an academic unit (Battistoni, Gelmon, Saltmarsh, Wergin, \& Zlotkowski, 2003; Kecskes, 2013). In
Figure 1

Strategic Thinking and Action - Nested and

Reinforcing Concepts

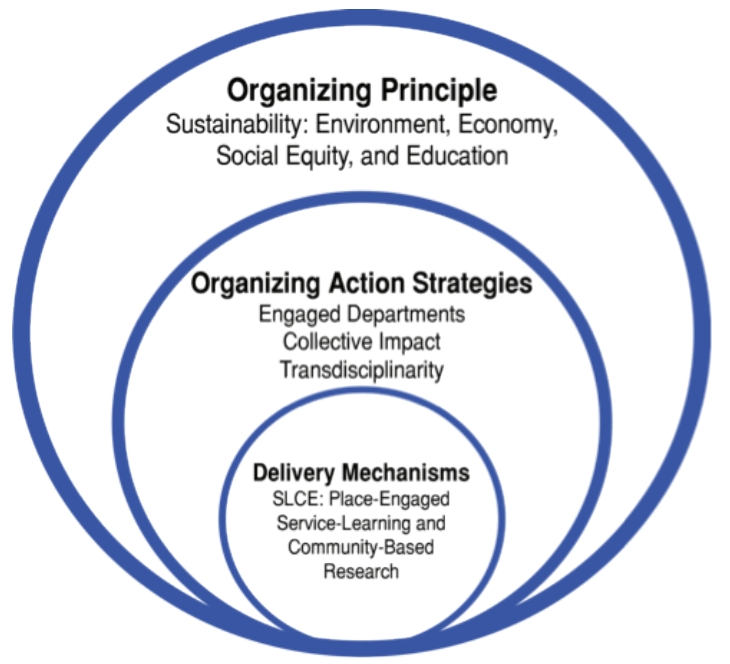

short, faculty in the unit work together with community partners on a common challenge by coupling complementary research strengths and SLCE coursework with students in multiple courses over time. An engaged department strategy can help positively modify the departmental ethos by leveraging individual faculty interests and capacity toward aggregated ends. Focusing departmental work on one or more prominent community-identified sustainability goals can leverage individual faculty research efforts toward more of a cohesive whole; deepen, connect, and broaden learning environments as students may work over time and via multiple courses in the major on one complex, longer-term sustainability project; and add complementary wisdom and knowledge toward the solution of compelling community-situated sustainability problems. Combining efforts and working in unison with departmental colleagues (and students, community partners, and others) can build synergy between/amongst individual faculty efforts. Intensive faculty research and teaching collaborations, replete with regular information feedback loops from community partners and students, can model for all participants the kinds of collaboration necessary to begin to successfully address complex sustainability issues.

One example of a nascent, successful engaged department effort is in Physics at Dickinson College, which recently received a large institutional grant based on its commitment to intentionally engage academic units in SLCE and communityengaged research in dialogue with local communities. Faculty in the department are interested in having students in the major learn more, and in 
different ways, about thermodynamics. To do so, undergraduates are utilizing common household materials to construct and test basic solar panels and other simple machines that save energy for homes. The Dickinson Physics students travel to local high schools and engage with students there to teach basic energy principles and assist students in the construction of cost- and energy-saving machines for application in their homes. The high school students then, in turn, will teach similar principles and build machines for home use with local middle school students. Additionally, multiple members of the Dickinson Physics department engage with local high school teachers via weekend intensive sessions on campus that focus on multiple topics, including the development of innovative energy-related teaching methods targeted toward college, secondary, and middle school students (H. Pfister, personal communication, February 17,2017$)$.

Successful strategies for engaging departments with salient sustainability topics in the community include taking stock of current SLCE efforts in the unit to identify overlaps and leverage potential synergies that have broad research and teaching applications; link courses and research efforts when appropriate; working with select community partners to identify sustainability issues of sufficient complexity and potential positive impact; and co-producing a coherent plan forward that has regular communication feedback loops embedded, among other strategies (for a comprehensive list of engaged department implementation strategies, see Kecskes \& Spring, 2006). Challenges to engaging departments can occur when unit norms do not value collaborative work; senior colleagues are unsympathetic or disinterested in community-connected activities; and/ or if there is no larger coordinating unit (or backbone organization) or additional staff support available to assist departmental faculty in the identifying, planning, communicating, executing, and tracking phases of the collective SLCE work of the department. Regarding this latter challenge, with a focus on the role of the backbone organization, we turn to our second organizing strategy - collective impact.

\section{Collective Impact}

Formalized collective impact approaches include five distinct features: agreement on a common agenda; shared methods of measuring; mutually reinforcing activities; open and continuous communication; and a "backbone organization" that provides logistical and overall partnership support (Kania \& Kramer, 2011). The backbone organization helps strategically bridge and connect larger- scale efforts into smaller place-based partnerships and actions. In the context of HEIs, the SLCE delivery mechanisms of place-engaged service-learning and community-based research can be particularly potent when leveraged into larger sustainabilityrelated community change efforts.

One such example of this approach is a sustainability project involving thirteen Canadian cities working together through Vibrant Communities Canada (VCC), the backbone organization, to bring together diverse groups from the business, nonprofit, volunteer, and citizen sectors to reduce poverty (Schwartz, Weaver, Pei, \& Miller, 2016). In 2011, Carleton University partnered with VCC in a project called Communities First: Impacts of Community Engagement (CFICE) to mobilize and leverage their engaged campuscommunity connections to combat entrenched sustainability issues. With broader-based support from VCC, CFICE was able to set up five distinct community-campus projects, called hubs, focusing on "poverty, violence against women, community-environmental sustainability, food security, and knowledge mobilization" (Schwartz et al., p.171). CFICE solicited proposals for SLCE projects from multiple universities and community partners focusing on the hub initiatives, thus leveraging and connecting ongoing and new SLCE efforts into the larger initiative.

Institutions of higher education are not only capable of offering a diverse variety of internal resources, but their unique position in communities provides them with opportunities to function as a backbone organization themselves while organizing around sustainability issues. Arizona State University (ASU) is an example of this institutional commitment to a unifying agenda around advancing collective well-being, connected directly to addressing the " 4 Es" of sustainability. ASU established the nation's first School of Sustainability in 2006 and has since acted as a backbone organization to not only bring students, community, and partner organizations together, but also to expand their collaboration to a global scale connecting other academic institutions throughout the world. In an open call-to-action letter, the ASU President Michael Crow (2007) announced:

[U]niversities must take the lead in addressing issues of sustainability. Academic communities cannot be removed from the front lines of social change, and our universities must serve as a forum for cultural, economic, political, and social reform. Universities are transformational catalysts for societal change and perform functions essential to our collective survival. ... (p. 8). 
It is clear from President Crow's call that intentionality is a key strength of the collective impact approach; other strengths include its unifying and adaptive approaches to leveraging formerly disconnected community change efforts. The work of the backbone organization is often critical to ensure collective program success. Utilizing other organizing action strategies such as the engaged department model can help HEIs institutionalize community-focused agendas and processes and reduce barriers of entry into key partnership agreements and collaborative sustainability efforts.

Effective HEI efforts are not incidental; they require a deep and sustained commitment by the institution. The absence of this commitment can quickly become a challenge. A weak or non-existent backbone organization at the center of the larger effort, as well as the fact that deeply entrenched sustainability issues often take a considerable amount of time to address, can also be significant challenges to the collective impact model.

\section{Transdisciplinarity}

While transdisciplinarity is a contested term, for the purposes of this essay our definition focuses on what we consider its two key characteristics relevant for SLCE. First, there are SLCE approaches that necessarily transcend the limits of a single disciplinary approach for knowledge production and application; this is often referred to as interdisciplinary - involving more than one discipline. Second, there are SLCE approaches that transcend the limits of disciplinarity itself. This suggests that valid and practical sources of wisdom and knowledge exist outside of traditional scholarly domains. This latter point necessitates the regular, active, and respectful integration of non-traditional communitybased knowledge sources into SLCE efforts from the outset. Similar to the idea of co-production (Ostrom, 1996) a transdisciplinary approach suggests that people who are affected by an issue should be directly involved in the definition of that concern and in the generation of strategies to address and monitor the issue. Indeed, Ruppert-Winkel and colleagues (2015) coined the term "transdisciplinary sustainability science" as a way to scientifically contribute to addressing social problems by integrating varied disciplinary knowledge (Boyer, 1996) from the natural and social sciences as well as community-level experienced-based knowledge as an appropriate way to address many sustainability concerns. In the context of properly identifying and addressing complex sustainability issues over time, adopting a transdisciplinary approach in SLCE research and teaching efforts is critically important; coupling this approach with a collective impact strategy, in the context of an engaged department has proved to be especially powerful.

An example of such intentional coupling is occurring at Portland State University (PSU) where faculty, staff, and administrators have sought to strategically link the university's commitment to sustainability with experience in SLCE in order to accelerate positive community change. In 2013, PSU's Institute for Sustainable Solutions (ISS) launched the Sustainable Neighborhood Initiative (SNI), which is informed by a collective impact organizing action strategy, to serve as a campuswide SLCE partnership broker. SNI functions as a backbone organization to bridge clusters of SLCE teaching and research projects - within and across disciplines and over multiple terms - in order to support cumulative impact on local sustainability issues (Holiday 2015). Through this initiative, PSU faculty and students have worked on SLCE projects around topics such as green building, renewable energy, youth literacy, community health, placemaking, bicycle and pedestrian transportation planning, economic development, and environmental monitoring (Sherman \& Beaudoin, 2016).

In 2014, SNI's collective, transdisciplinary approach was coupled with an engaged department. Multiple faculty from public administration (PA) were particularly interested in avoiding the common "one and done" SLCE project implementation model; therefore, they worked with SNI to intentionally focus their curriculum and research efforts over multiple academic terms in the historically underserved Lents neighborhood in outer Southeast Portland. Over three years, nine sections of connected undergraduate PA courses involving 300 students and five faculty have responded to community-driven requests to assist neighborhood organizations and residents build local assets that address pressing sustainability issues. PA faculty and students have worked with residents to convert an unused city lot into a community orchard; build capacity for diversity and social equity in an established neighborhood nonprofit; and focus on a climate resilience project to reduce the negative impacts of urban stream flooding. These SLCE efforts have been integrated into complementary efforts led by local government agencies as well.

Working in this collective and coordinated fashion over the past three years has been both challenging and effective. For example, predictable obstacles encountered in shorter-term SLCE efforts can get compounded when the partnership work intensifies and the project time frame increases. As the number of partners expands, the management of outcome expectations and communication com- 
plexities may also rise. However, PSU researchers have documented significant positive impact in multiple areas, including student civic learning, faculty collaboration, community partner and resident capacity-building, and institutional commitment (Kecskes, Sumner, Elliott, \& Ackerman, 2016).

\section{Sustainability and SLCE: Our Collective Path Forward}

Over 900 colleges and universities are members of the Association for the Advancement of Sustainability in Higher Education (AASHE) and have adopted sustainability as an institutional priority, in terms of pursuing operational efficiencies and/ or by integrating sustainability into research and curricular activities. Simultaneously, nearly 1,100 colleges and universities are members of Campus Compact, with several hundred more associated with other national and international higher education associations focusing on SLCE. Our call hopes to bring these efforts together, with intention and at every level: from the community and classroom to the most influential halls of policy development.

While certainly not perfect and still in an emergent phase, efforts such as those being undertaken by colleges and universities described above are beginning to generate significant results by utilizing sustainability as an overarching institutional organizing principle and SLCE strategies as the delivery mechanisms for realizing change on their campuses and in their communities. We believe there is promise in implementing a combination of the three organizing action strategies outlined here - engaged departments, collective impact, and transdisciplinary models - to engage a diverse set of faculty, increasing numbers of students, and targeted groups of community partners to share a common language and pursue a common vision for sustaining our planet and all its species.

\section{Note}

The authors acknowledge and appreciate the thoughtful feedback from the SLCE-FDP leadership team.

\section{References}

Allen, K. (2017, January 12). ILO warns of rise in social unrest and migration as inequality widens. The Guardian. Retrieved from https://www.theguardian. com/business/2017/jan/12/ilo-warns-of-rise-in-socialunrest-and-migration-as-inequality-widens

Battistoni, R. M., Gelmon, S. B., Saltmarsh, J., Wergin, J., \& Zlotkowski, E. (2003). The engaged department toolkit. Providence, RI: Campus Compact.
Boyer, E. (1996). The scholarship of engagement. Bulletin of the American Academy of Arts and Sciences, 49(7), 18-33.

Cook, J., Oreskes, N., Doran, P. T., Anderegg, W. R., Verheggen, B., Maibach, E. W. et al. (2016). Consensus on consensus: A synthesis of consensus estimates on human-caused global warming. Environmental Research Letters, 11(4), 048002.

Crow, M. (2007). Sustainability: An organizing principle for colleges and universities. University Business, 10(6), 8-10.

Dubb, S., McKinley, S., \& Howard, T. (2013). The anchor dashboard: Aligning institutional practices to meet low-income community needs. Takoma Park, MD: The Democracy Collaborative.

Holliday, M., DeFalco, T., \& Sherman, J. (2015). Putting impact first: Community-university partnerships to advance authentic neighborhood sustainability. Metropolitan Universities, 26(3), 79-104.

Howard, J., \& Stanlick, S. (2015). A call for a national strategic plan. Michigan Journal of Community Service Learning, 22(1), 128-131.

Kania, J., \& Kramer, M. (2011). Collective impact. Stanford Social Innovation Review. Retrieved from http:// ssir.org/articles/entry/collective_impact

Kecskes, K. (2013). The engaged department and higher education reform: Research, theory, and transformation of the academic unit. In P. Clayton, R. Bringle, \& J. Hatcher (Eds.), Research on Service Learning: Conceptual frameworks and assessment (pp. 471504). Sterling, VA: Stylus.

Kecskes, K., Sumner, R., Elliott, E., \& Ackerman, A. (2016). A year-long journey in the orchard: Growing community amid the brambles. In B. D. WorthamGavin, J. Allen, \& J. Sherman (Eds.), Sustainable solutions: Community-university partnerships (pp. 11-34). Sheffield, UK: Greenleaf.

Kecskes, K., \& Spring, A. (2006). Continuums of engagement at Portland State University: An institution-wide initiative to support departmental collaboration for the common good. In K. Kecskes (Ed.), Engaging departments: Moving faculty culture from private to public, individual to collective focus for the common good (pp. 219-242). Bolton, MA: Anker.

NASA, Global Climate Change (2017). Retrieved from https://climate.nasa.gov/scientific-consensus/

Ostrom, E. (1996). Crossing the great divide: Coproduction, synergy, and development. World Development, 24, 1073-1087.

Oxfam. (2017). An economy for the $99 \%$. Retrieved from https://www.oxfam.org/en/research/economy-99

Ruppert-Winkel, C., Arlinghaus, R., Deppisch, S., Eisenack, K., Gottschlich, D., Hirschl, B. et al. (2015). Characteristics, emerging needs, and challenges of transdisciplinary sustainability science: Experiences from the German Social-Ecological Research Program. Ecology and Society, 20(3), 13.

Schwartz, K., Weaver, L., Pei, N., \& Miller, A. (2016). Community-campus partnerships, collective impact, 
and poverty reduction. Community Development, 47(2), 167-180.

Sherman, J., \& Beaudoin, F. (2016). Higher education as a driver for urban sustainability outcomes: The role of Portland State University's Institute for Sustainable Solutions. In B. D. Worthman- Galvin, J. Allen, \& J. Sherman (Eds.), Sustainable solutions: Communityuniversity partnerships (pp. 152-172). Sheffield, UK: Greenleaf.

Siemers, C. K., Harrison, B., Clayton, P. H., \& Stanley, T. (2015). Engaging place as partner. Michigan Journal of Community Service Learning, 22(1), 101-104.

Thomashow, M. (2014). The nine elements of a sustainable campus. Cambridge, MA: MIT Press.

UNESCO. (2016). Education for sustainable development. Retrieved from http://en.unesco.org/themes/ education-sustainable-development

World Commission on Environment and Development. (1990). Our common future. Retrieved from https:// en.wikipedia.org/wiki/Our_Common_Future

\section{Authors}

KEVIN KECSKES (kecskesk@pdx.edu) is associate professor of Public Administration in the Mark O. Hatfield School of Government at Portland State University (PSU) where he teaches masters and doctoral students and directs the department's undergraduate academic program in civic leadership. For over a decade, he has provided university-wide leadership in various positions at PSU including associate vice provost for Engagement and director for Community-University Partnerships. He is on the editorial board of the Journal of Public Scholarship in Higher Education and edited Engaging Departments: Moving Faculty Culture from Private to Public, Individual to Collective Focus for the Common Good (2006).
JENNIFER JOYALLE (joyalle@pdx.edu) is a doctoral student in Portland State University's Public Affairs and Policy doctoral program where she is studying organizational change, networked governance, and community engagement in the field of K-20 public education. She is currently an instructor in the department of public administration's civic leadership program; formerly, she taught in PSU's University Studies Senior Capstone program. For over a decade, she taught in the Portland Public Schools as a middle school teacher in a service-learning program based on relationships, leadership, and community building.

ERIN ELLIOTT (elliott7@pdx.edu) is a doctoral candidate in Portland State University's Public Affairs and Policy doctoral program where her research centers on critical nonprofit theory and citizenship studies. She is an instructor in the department of public administration's civic leadership program, and also employs a community-based learning approach to teach other University Studies courses at PSU. She has worked extensively in the nonprofit sector. Most recently, she co-authored a book chapter on community-based learning and sustainability in Sustainable Solutions: CommunityUniversity Partnerships (2016).

JACOB D. B. SHERMAN (jdbsherman@gmail. com) is the housing program coordinator for the Portland Housing Bureau's Lents Stabilization Initiative in the City of Portland. Previously, he served as program manager and sustainability curriculum coordinator at Portland State University's Institute for Sustainable Solutions. He is co-editor of the Sustainable Solutions book series (2016) and is currently completing a second master's degree in business administration at PSU. 